\title{
Use of DNA microarray chips for the rapid detection of Mycobacterium tuberculosis resistance to rifampicin and isoniazid
}

\author{
PEIJUN TANG ${ }^{1,2^{*}}$, XIAFANG WANG $^{2 *}$, XINGHUA SHEN $^{1,2}$, MEIHUA SHI $^{2}$, \\ XUEFENG ZHU ${ }^{2}$, XIN YU ${ }^{2}$, JIA LIU ${ }^{2}$, CHUNHUA LING ${ }^{1}$ and MEIYING WU ${ }^{2}$ \\ ${ }^{1}$ Department of Respiration, The First Hospital Affiliated to Soochow University; \\ ${ }^{2}$ Department of Tuberculosis, The Affiliated Infectious Hospital of Soochow University, \\ The Fifth People's Hospital of Suzhou, Suzhou, Jiangsu 215007, P.R. China
}

Received October 11, 2015; Accepted January 20, 2017

DOI: $10.3892 / e t m .2017 .4250$

\begin{abstract}
The objective of the present study was to evaluate the potential development of DNA microarray chips to detect rifampicin (RFP) and isoniazid (INH) resistance in Mycobacterium tuberculosis (MTB), using samples from clinical tuberculosis (TB) patients in Soochow City, China. The sputum samples of 42 patients with TB in the Affiliated Hospital of Infectious Diseases of Soochow University (Soochow, China) were collected. The conventional Lowenstein-Jensen culture medium (Gold Standard) was used to assess drug sensitivity using the absolute concentration method. GeeDom MTB drug detection kits were also used to create a DNA microarray chip and examine the RFP-resistance associated gene mutation points $r p o B-R R D R 511,513,516,526,531$ and 533 , and the INH-resistance associated gene mutation points katG315 and inhA-15 of the sputum samples. Compared with the results from the absolute concentration method, the susceptibility and specificity of RFP sensitivity detected by the DNA microarray chip were 92.8 and $93.8 \%$, respectively. The susceptibility and specificity of INH sensitivity detected were 66.7 and $81 \%$, respectively. The $r p o B-R R D R 526,531$ mutations were the primary causes of MTB RFP resistance and the katG315 mutation was the primary cause of INH resistance. The detection of $r p o B$ and $k a t G$ gene mutation points by
\end{abstract}

Correspondence to: Dr Meiying Wu, Department of Tuberculosis, The Affiliated Infectious Hospital of Soochow University, The Fifth People's Hospital of Suzhou, 2 Xier Road, Suzhou, Jiangsu 215007, P.R. China

E-mail: tangpeipei001@163.com

Dr Chunhua Ling, Department of Respiration, The First Hospital Affiliated to Soochow University, 188 Shizi Street, Suzhou, Jiangsu 215007, P.R. China

E-mail: lingch1108@sohu.com

${ }^{*}$ Contributed equally

Key words: DNA micro-assay chip, tuberculosis, rifampicin, isoniazid, drug resistance a DNA microarray chip may be used as a rapid, accurate and bulk clinical detection method for RFP and INH resistance in MTB. This is very valuable for the control of TB epidemics.

\section{Introduction}

The spread of drug-resistant clinical tuberculosis (TB) and its co-infection with HIV have seriously affected TB prevention and treatment (1). Inherently, this has meant deterioration in the control of epidemics. As anti-TB drugs that were identified early for clinical use, rifampicin (RFP) and isoniazid (INH) have served an important therapeutic role for TB treatment $(2,3)$. Statistical data from WHO indicates that the drug resistance of TB to the first-line drugs INH and RFP is 13.3 and $6.3 \%$, respectively (4). Research has also suggested that in recent years TB clinical strains have demonstrated high levels of RFP (13.3\%), INH (24.6\%) and multi-drug (10.5\%) resistance (5). At present, there are a number of methods used to detect Mycobacterium tuberculosis (MTB) drug resistance, but most are time-consuming (6). The absolute concentration, or proportional, method requires cultivation of the bacterium for 2-3 months before the drug sensitivity of a strain is able to be determined (7). The BACTEC method (8) only takes 2-4 weeks, but this remains too slow for clinical requirements.

MTB resistance to RFP is primarily associated with a mutation in the $r p o B$ gene $(9,10)$. If the $r p o B$ gene encoding the $\beta$ subunit of RNA polymerase mutates, RFP and the $\beta$ subunit cannot combine to produce the antibacterial effect. This results in MTB resistance to RFP. At present, 70 mutation sites have been identified in the $r p o B$ gene in patients diagnosed with MTB resistance to RFP $(9,11,12)$. Of these, $>95 \%$ are associated with drug resistance in the rpoB gene codons 507-533, which consist of 81 bases; this is known as the rifampicin resistance-determining region (RRDR). The 531 Ser, 526 His and 516 Asp codons are considered the key mutation locations for RFP resistance $(13,14)$. Thus, there is great value in an early clinical diagnosis of resistance, to establish a rapid detection method of $r p o B$ gene mutations in this region and the relative likelihood of RFP resistance.

Mutations of various relevant enzyme-encoding genes in MTB, which encode the enzymes involved in the INH pathway, create resistance to INH. The genes involved primarily include 
kat $G, \operatorname{inh} A, \operatorname{Kas} A, n d h$ and $\operatorname{ahpC}(15,16)$. Among these, $k a t G$ encodes catalase-peroxidase, which is involved in the transition of INH into its active form. inhA encodes enoyl reductase, which is involved in mycolic acid biosynthesis. $k a t G$ and $i n h A$ are the primary molecular factors in MTB resistance to INH. Molecular biological detection techniques may be used to detect the detailed molecular characteristics of kat $G$ and inhA gene mutations, which may provide rapid early diagnosis for the treatment of drug-resistant TB. The mutation spectrum and mutation rates of kat $G$ and inhA have regional differences, but katG315 and inh $A-15$ are the most common mutation sites $(17,18)$. Therefore, the detection of mutations at these two sites has potential application in determination of INH resistance.

In the present study, a DNA microarray chip was prepared to detect the mutation sites, based on the gene mutations associated with the molecular mechanisms of RFP and INH resistance. The DNA microarray chip technique was used to detect RFP and INH resistance of clinical TB strains in Soochow City (China) and the results were compared with drug sensitivity results from the absolute concentration method, based on Lowenstein-Jensen cultivation. The value of rapid detection of RFP and INH resistance in TB clinical strains within Soochow City (by DNA microarray chip) was considered, in terms of the method's ability to promote the early diagnosis and treatment of TB, decrease TB morbidity and increase the recovery rates from TB in Soochow City.

\section{Materials and methods}

Research population. From January 2014 to December 2014, the sputum samples were collected from 42 patients (male/female, 27/15; age range, 18-75 years) with TB in the Affiliated Hospital of Infectious Diseases of Soochow University (Soochow, China). All the patients were negative for acute hepatitis B, antibodies (Abs) to Hepatitis C virus (HCV), Hepatitis D virus (HDV), human immunodeficiency virus (HIV), combined tumor and other symptoms of liver damage such as autoimmune disease, alcoholic liver disease and drug-induced hepatitis. Our study was approved by the local ethics committee, and all patients provided their written informed consent.

Conventional drug sensitivity test. Following conventional processing (5), the patients' sputum samples were placed in a BACTEC MGIT-960 MTB culture machine (BD Diagnostics, Sparks, MD, USA), and acid-fast staining was performed to identify TB-positive samples (19). Following cultivation, the MTB was assessed for drug sensitivity using a Lowenstein-Jensen culture medium (Cell Biotech Co., Ltd., Jinan, China) (5). The cultivated MTBs were subjected to three treatments of RFP and INH (Longtai Corporation, Jilin, China) each, based on concentration (RFP: 0, 50 and $250 \mu \mathrm{g} / \mathrm{ml}$; INH: 0, 1 and $10 \mu \mathrm{g} / \mathrm{ml}$ ). Following a 4-week cultivation period, the following criteria were used to determine the sensitivity: Counts $>200$, drug sensitive; counts $\leq 200$, drug resistant. 'Moderate sensitivity' was determined to indicate drug resistance.

Detection by DNA microarray chip. This study was based on the designing of oligonucleotide probes which can specifically detect the mutations on the promoter of $r p o B$, KatGandinhA. Briefly, the DNA microarray chip technique (20) was used to test mutations in the rpoBgene at the 511, 513, 526, 531 and 533 codons (common mutation sites) to give an indication of RFP resistance in the RRDR. For INH resistance, the katG315 and inhA-15 mutation sites were assessed. The standard protocol of the GeeDom MTB drug detection kits (18000065.001; CapitalBio Corporation, Beijing, China) were followed to assess the RFP and INH resistance of the samples. The nucleic acid was extracted using a GeeDom Extractor 36 rapid nucleic acid extraction instrument (CapitalBio Corporation). This was followed by polymerase chain reaction (PCR) amplification. The sequence of primers is respectively forward AGGCGA TCACACCGCAGACGT and reverse CGAGCCGATCAG ACCGATGT for amplifying $r p o B$ fragment, forward GAT CGTCGGCGGTCACACTTTC and reverse CTCTTCGTC AGCTCCCACTCGTAG for amplifying KatG fragment, and forward CACCCGCAGCCAGGGCC and CGATCC CCCGGTTTCCTCC for amplifying inhA fragment. The programme for PCR is as follows: Pre-denaturation $94^{\circ} \mathrm{C}$ for $4 \mathrm{~min}$; 30 cycle: Denaturation $94^{\circ} \mathrm{C}$ for $40 \mathrm{sec}$, annealing reaction $56^{\circ} \mathrm{C}$ for $50 \mathrm{sec}$, elongation reaction $72^{\circ} \mathrm{C} 60 \mathrm{sec}$; and elongation reaction $72^{\circ} \mathrm{C}$ for $10 \mathrm{~min}$. Once combined with a hybridization buffer (CapitalBio Corporation), the products were placed in a BioMixer II chip hybridization instrument (Core Life Sciences, Inc., Irvine, CA, USA) for hybridization. Products were then put in a lideWasher8 chip dry cleaning instrument (CapitalBio Corporation) for washing and drying. Finally, the chip was placed in the TB drug resistance chip identification system (CapitalBio Corporation) for scanning and interpretation (LuxScanTM 10K/B software, CapitalBio Corporation). The interpreted results and chip information were recorded in detail according to the standard protocol. Every five repeated hybrid grid points correspond to one cell of specific content. The assay was performed in triplicate.

Statistical analysis. Statistical analyses were performed using GraphPad Prism 6.0 software (GraphPad Software, Inc., San Diego, CA, USA) showing mean \pm standard error of the mean. Mann-Whitney U tests of SSPS 12.0 (SPSS, Inc., Chicago, IL, USA) were used to assess the difference between different groups. A two-tailed $\mathrm{P}<0.05$ was considered statistically significant.

\section{Results}

RFP and INH resistance of MTB according to the conventional drug sensitivity test. A conventional drug sensitivity test using the Lowenstein-Jensen culture medium demonstrated that of the 42 positive TB samples tested, 15 were sensitive and 27 resistant to RFP. In total, 21 samples were sensitive and 21 samples resistant to INH.

Detection of $M T B$ rpoB-RRDR relevant mutation sites according to the DNA microarray chip. The mutations and wild type detection spectrum are presented in Fig. 1, and Table I summarizes the results. The results were estimated based on every five repeated hybrid grid points correspond to one cell of specific content. There were three $(7.1 \%)$ mutations of the $r p o B$ gene at RRDR-526 (CAC $\rightarrow$ TA2.3C; His $\rightarrow$ Tyr; H526Y), 
A

\begin{tabular}{|c|c|}
\hline $\mathrm{QC}$ & $\mathrm{EC}$ \\
\hline $\mathrm{BC}$ & $r p o \mathrm{~B}$ IC \\
\hline Mycobacterium & Myobocterium Twercelooit \\
\hline $511 \mathrm{WT}$ & $511(\mathrm{~T} \rightarrow \mathrm{C})$ \\
\hline $513 \mathrm{WT}$ & $513(\mathrm{C} \rightarrow \mathrm{A})$ \\
\hline $516 \mathrm{WT}$ & $513(\mathrm{~A} \rightarrow \mathrm{C})$ \\
\hline $533 \mathrm{WT}$ & $533(\mathrm{~T} \rightarrow \mathrm{C})$ \\
\hline $531 \mathrm{WT}$ & $531(\mathrm{C} \rightarrow \mathrm{T})$ \\
\hline $526 \mathrm{WT}$ & $531(\mathrm{C} \rightarrow \mathrm{G})$ \\
\hline $526(\mathrm{C} \rightarrow \mathrm{T})$ & $526(\mathrm{C} \rightarrow \mathrm{G})$ \\
\hline $526(\mathrm{~A} \rightarrow \mathrm{T})$ & $526(\mathrm{~A} \rightarrow \mathrm{G})$ \\
\hline $516(\mathrm{~A} \rightarrow \mathrm{T})$ & $516(\mathrm{G} \rightarrow \mathrm{T})$ \\
\hline $516(\mathrm{~A} \rightarrow \mathrm{G})$ & $\mathrm{NC}$ \\
\hline $\mathrm{EC}$ & $\mathrm{QC}$ \\
\hline
\end{tabular}

C

\begin{tabular}{|c|c|}
\hline $\mathrm{QC}$ & $\mathrm{EC}$ \\
\hline $\mathrm{BC}$ & $r$ poB IC \\
\hline Mycobacterium & Myeotacsmim Twercelosis \\
\hline $511 \mathrm{WT}$ & $511(\mathrm{~T} \rightarrow \mathrm{C})$ \\
\hline $513 \mathrm{WT}$ & $513(\mathrm{C} \rightarrow \mathrm{A})$ \\
\hline $516 \mathrm{WT}$ & $513(\mathrm{~A} \rightarrow \mathrm{C})$ \\
\hline $533 \mathrm{WT}$ & $533(\mathrm{~T} \rightarrow \mathrm{C})$ \\
\hline $531 \mathrm{WT}$ & $531(\mathrm{C} \rightarrow \mathrm{T})$ \\
\hline $526 \mathrm{WT}$ & $531(\mathrm{C} \rightarrow \mathrm{G})$ \\
\hline $526(\mathrm{C} \rightarrow \mathrm{T})$ & $526(\mathrm{C} \rightarrow \mathrm{G})$ \\
\hline $526(\mathrm{~A} \rightarrow \mathrm{T})$ & $526(\mathrm{~A} \rightarrow \mathrm{G})$ \\
\hline $516(\mathrm{~A} \rightarrow \mathrm{T})$ & $516(\mathrm{G} \rightarrow \mathrm{T})$ \\
\hline $516(\mathrm{~A} \rightarrow \mathrm{C})$ & $\mathrm{NC}$ \\
\hline $\mathrm{EC}$ & $\mathrm{QC}$ \\
\hline
\end{tabular}

$\mathbf{E}$

\begin{tabular}{|c|c|}
\hline QC & EC \\
\hline $\mathrm{BC}$ & $r p o B$ IC \\
\hline Mycobacterium & Myrobuceritum Therecelosis \\
\hline 511WT & $511(\mathrm{~T} \rightarrow \mathrm{C})$ \\
\hline 513WT & $513(C \rightarrow A)$ \\
\hline $516 \mathrm{WT}$ & $513(\mathrm{~A} \rightarrow \mathrm{C})$ \\
\hline 533WT & $533(\mathrm{~T} \rightarrow \mathrm{C})$ \\
\hline 531WT & $531(C \rightarrow T)$ \\
\hline 526WT & $531(\mathrm{C} \rightarrow \mathrm{G})$ \\
\hline $526(C \rightarrow T)$ & $526(C \rightarrow G)$ \\
\hline $526(\mathrm{~A} \rightarrow \mathrm{T})$ & $526(A \rightarrow G)$ \\
\hline $516(\mathrm{~A} \rightarrow \mathrm{T})$ & $516(\mathrm{G} \rightarrow \mathrm{T})$ \\
\hline $516(A \rightarrow G)$ & $\mathrm{NC}$ \\
\hline$E C$ & $Q C$ \\
\hline
\end{tabular}

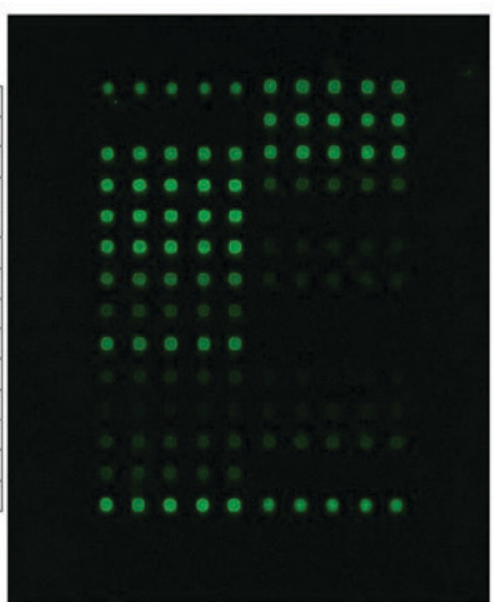

B

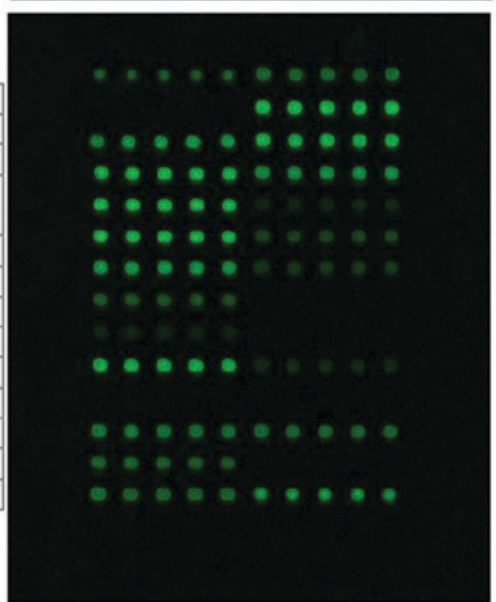

\begin{tabular}{|c|c|}
\hline QC & EC \\
\hline BC & $r p o B$ IC \\
\hline Mycobacterium & Mycobocerim Twerculoais \\
\hline $511 \mathrm{WT}$ & $511(\mathrm{~T} \rightarrow \mathrm{C})$ \\
\hline $513 \mathrm{WT}$ & $513(\mathrm{C} \rightarrow \mathrm{A})$ \\
\hline $516 \mathrm{WT}$ & $513(\mathrm{~A} \rightarrow \mathrm{C})$ \\
\hline $533 \mathrm{WT}$ & $533(\mathrm{~T} \rightarrow \mathrm{C})$ \\
\hline $531 \mathrm{WT}$ & $531(\mathrm{C} \rightarrow \mathrm{T})$ \\
\hline $526 \mathrm{WT}$ & $531(\mathrm{C} \rightarrow \mathrm{G})$ \\
\hline $526(\mathrm{C} \rightarrow \mathrm{T})$ & $526(\mathrm{C} \rightarrow \mathrm{G})$ \\
\hline $526(\mathrm{~A} \rightarrow \mathrm{T})$ & $526(\mathrm{~A} \rightarrow \mathrm{G})$ \\
\hline $516(\mathrm{~A} \rightarrow \mathrm{T})$ & $516(\mathrm{G} \rightarrow \mathrm{T})$ \\
\hline $516(\mathrm{~A} \rightarrow \mathrm{G})$ & $\mathrm{NC}$ \\
\hline $\mathrm{EC}$ & $\mathrm{QC}$ \\
\hline & \\
&
\end{tabular}

D

\begin{tabular}{|c|c|}
\hline $\mathrm{QC}$ & EC \\
\hline $\mathrm{BC}$ & poB $\mathrm{IC}$ \\
\hline Mycobacterium & Mycobacerima Tutercolosis \\
\hline $511 \mathrm{WT}$ & $511(\mathrm{~T} \rightarrow \mathrm{C})$ \\
\hline $513 \mathrm{WT}$ & $513(\mathrm{C} \rightarrow \mathrm{A})$ \\
\hline $516 \mathrm{WT}$ & $513(\mathrm{~A} \rightarrow \mathrm{C})$ \\
\hline $533 \mathrm{WT}$ & $533(\mathrm{~T} \rightarrow \mathrm{C})$ \\
\hline $531 \mathrm{WT}$ & $531(\mathrm{C} \rightarrow \mathrm{T})$ \\
\hline $526 \mathrm{WT}$ & $531(\mathrm{C} \rightarrow \mathrm{G})$ \\
\hline $526(\mathrm{C} \rightarrow \mathrm{T})$ & $526(\mathrm{C} \rightarrow \mathrm{G})$ \\
\hline $526(\mathrm{~A} \rightarrow \mathrm{T})$ & $526(\mathrm{~A} \rightarrow \mathrm{G})$ \\
\hline $516(\mathrm{~A} \rightarrow \mathrm{T})$ & $516(\mathrm{G} \rightarrow \mathrm{T})$ \\
\hline $516(\mathrm{~A} \rightarrow \mathrm{G})$ & $\mathrm{NC}$ \\
\hline $\mathrm{EC}$ & $\mathrm{QC}$ \\
\hline
\end{tabular}

$\mathbf{F}$

\begin{tabular}{|c|c|}
\hline $\mathrm{QC}$ & EC \\
\hline $\mathrm{BC}$ & $r$ poB IC \\
\hline Mycobactenum & Mycotocterim Tuterculocis \\
\hline $511 \mathrm{WT}$ & $511(\mathrm{~T} \rightarrow \mathrm{C})$ \\
\hline $513 \mathrm{WT}$ & $513(\mathrm{C} \rightarrow \mathrm{A})$ \\
\hline $516 \mathrm{WT}$ & $513(\mathrm{~A} \rightarrow \mathrm{C})$ \\
\hline $533 \mathrm{WT}$ & $533(\mathrm{~T} \rightarrow \mathrm{C})$ \\
\hline $531 \mathrm{WT}$ & $531(\mathrm{C} \rightarrow \mathrm{T})$ \\
\hline $526 \mathrm{WT}$ & $531(\mathrm{C} \rightarrow \mathrm{G})$ \\
\hline $526(\mathrm{C} \rightarrow \mathrm{T})$ & $526(\mathrm{C} \rightarrow \mathrm{G})$ \\
\hline $526(\mathrm{~A} \rightarrow \mathrm{T})$ & $526(\mathrm{~A} \rightarrow \mathrm{G})$ \\
\hline $516(\mathrm{~A} \rightarrow \mathrm{T})$ & $516(\mathrm{C} \rightarrow \mathrm{T})$ \\
\hline $516(\mathrm{~A} \rightarrow \mathrm{G})$ & $\mathrm{NC}$ \\
\hline $\mathrm{EC}$ & $\mathrm{QC}$ \\
\hline
\end{tabular}
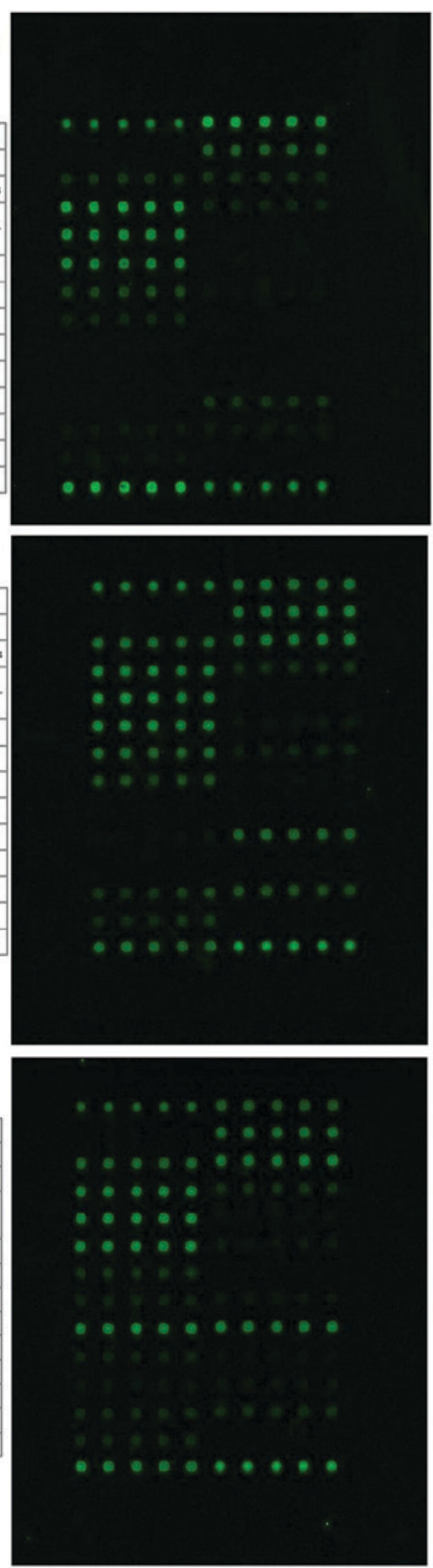

Figure 1. Detection spectrums of the microarray chip for the $r p o B$-RRDR relevant mutation points. The microarray chip spectrums present the samples with mutation(s) at: (A) WT MTB rpoB-RRDR 511, 513, 516, 526, 531 and 533,(B) MTB rpoB-RRDR 526 (CAC $\rightarrow$ CGC), (C) MTB $r p o B$-RRDR 526 (CAC $\rightarrow$ TAC), (D) MTB $r p o B$-RRDR 526 (CAC $\rightarrow$ GAC), (E) MTB rpoB-RRDR 531 (TCG $\rightarrow$ TTG) and (F) MTB rpoB-RRDR 531 (TCG $\rightarrow$ TGG). The contents of the table on the left side correspond to the microarray hybridization dot matrix on the right side in each figure. Every five repeated hybrid grid points correspond to one cell of specific content. RRDR, rifampicin resistance-determining region; MTB, Mycobacterium tuberculosis; QC, chip preparation quality control; EC, chip hybridization quality control; BC, blank comparison quality control; IC, targeted gene amplification quality control; WT, wild type.

one mutation $(2.4 \%)$ at RRDR-526 $(\mathrm{CAC} \rightarrow \mathrm{GAC}$; His $\rightarrow \mathrm{Asp}$; H526D), 20 mutations (47.6\%) at RRDR-531 (TCG $\rightarrow$ TTG; $\mathrm{Ser} \rightarrow$ Leu; S531L) and one mutation (2.4\%) at RRDR-531 $(\mathrm{TCG} \rightarrow \mathrm{TGG}$; Ser $\rightarrow$ Trp; S531W). Furthermore, there were 17 mutations (40.5\%) for which the RRDR-511, 513, 526, 531, and 533 mutation sites were all wild type (WT).

Detection of MTB katG315 and inhA-15 mutation points according to the DNA microarray chip. The microarray detection spectrums for the $\operatorname{Kat} G 315(\mathrm{G} \rightarrow \mathrm{C})$ mutation and the $\operatorname{inh} A(\mathrm{C} \rightarrow \mathrm{T})$ mutations are presented in Fig. 2, and Table II summarizes the results. Similarly, the results were estimated based on every five repeated hybrid grid points correspond to one cell of specific content. There were 26 mutations $(61.9 \%)$ of $k a t G 315$ (AGC $\rightarrow$ ACC; Ser $\rightarrow$ Thr; S315T), 16 cases $(38.1 \%)$ of inhA-15 and katG315 WTs, 1 mutation $(2.4 \%)$ of inhA-15 $(\mathrm{C} \rightarrow \mathrm{T})$ and 41 cases (97.6\%) of inhA-15 WT (Fig. 2). Thus, the mutations of katG315 (AGC $\rightarrow$ ACC) were more common, compared 
Table I. Microarray chip detection of mutations in Mycobacterium tuberculosis rpoB-RRDR relevant mutation sites for the 42 samples.

\begin{tabular}{|c|c|c|c|c|}
\hline rpoBcodon mutation & Codon variation & Amino acid variation & Strain no. & Percentage, $\%$ \\
\hline \multirow[t]{4}{*}{ RRDR-531 } & $\mathrm{CAC} \rightarrow \mathrm{TAC}$ & His $\rightarrow$ Tyr & 3 & 7.1 \\
\hline & $\mathrm{CAC} \rightarrow \mathrm{GAC}$ & His $\rightarrow$ Asp & 1 & 2.4 \\
\hline & $\mathrm{TCG} \rightarrow \mathrm{TTG}$ & $\mathrm{Ser} \rightarrow$ Leu & 20 & 47.6 \\
\hline & $\mathrm{TCG} \rightarrow \mathrm{TGG}$ & $\mathrm{Ser} \rightarrow \operatorname{Trp}$ & 1 & 2.4 \\
\hline $\begin{array}{l}\text { RRDR-511, 513, } \\
516,526,531,533\end{array}$ & No change & No change & 17 & 40.5 \\
\hline
\end{tabular}

RRDR, rifampicin resistance-determining region.

Table II. Microarray chip detection of KatG315 and inhA-15 mutation points for the 42 samples.

\begin{tabular}{|c|c|c|c|c|}
\hline Codon or gene locus & Codon or gene locus variation & Amino acid variation & Strain no. & Percentage, $\%$ \\
\hline \multirow[t]{2}{*}{ KatG315 } & $\mathrm{AGC} \rightarrow \mathrm{ACC}$ & $\mathrm{Ser} \rightarrow \operatorname{Thr}(\mathrm{S} 315 \mathrm{~T})$ & 26 & 61.9 \\
\hline & WT & - & 16 & 38.1 \\
\hline \multirow[t]{2}{*}{$\operatorname{inh} A-15$} & $\mathrm{C} \rightarrow \mathrm{T}$ & - & 1 & 2.4 \\
\hline & WT & - & 41 & 97.6 \\
\hline
\end{tabular}

Table III. Susceptibility and specificity of DNA microarray chip on the determination of RFP and INH R/S compared with the standard method of Lowenstein-Jensen cultivation for the 42 samples.

\begin{tabular}{lccc}
\hline & $\begin{array}{c}\text { Determination by Lowenstein- } \\
\text { Jensen cultivation }\end{array}$ & $\begin{array}{c}\text { Determination by DNA } \\
\text { microarray chip, R/S }\end{array}$ & Susceptibility, \% \\
\hline RFP resistance & 26 & $24 / 2$ & Specificity, \% \\
RFP sensitivity & 16 & $1 / 15$ & 92.3 \\
Total & 42 & $25 / 17$ & 93.8 \\
INH resistance & 21 & $14 / 7$ & 66.7 \\
INH sensitivity & 21 & $4 / 17$ & 81.0 \\
Total & 42 & $18 / 24$ & \\
\hline
\end{tabular}

RFP, rifampicin; INH, isoniazid; R/S, resistance/sensitivity.

with the inhA-15 mutation mutations $(\mathrm{C} \rightarrow \mathrm{T})$, and accounted for $96.3 \%$ of all the mutations associated with drug resistance.

Reliability of DNA microarray chip for drug sensitivity diagnosis. Results from the Lowenstein-Jensen cultivation method (5) were compared with the results from the DNA microarray chip detection. The susceptibility and specificity for RFP resistant strains were 92.3 and $93.8 \%$, respectively, when diagnosed by DNA microarray chip detection. The susceptibility and specificity for the INH resistant strains were 66.7 and $81 \%$, respectively (Table III).

\section{Discussion}

RFP and INH are the primary first-line anti-TB drugs. However, the application and effectiveness of these drugs has been greatly impacted by the increase in drug resistance. Statistical data from $\mathrm{WHO}$ indicates that the drug resistance of TB to these first-line drugs was 13.3 and $6.3 \%$, respectively (4). A previous study has also suggested that in TB clinical strains demonstratehigh levels of RFP (13.3\%), INH (24.6\%), and multi-drug (10.5\%) resistance (5). The conventional drug sensitivity assessment takes a long time and is unable to provide prompt guidance for appropriate clinical treatment $(7,8)$. Thus, the potential rapid detection of RFP and INH resistance by MTB would be impactful. Molecular biological techniques like PCR-single strand confirmation polymorphism (SSCP) are easy, rapid and inexpensive, but may only detect gene mutations; they are generally unable to determine the mutation points and the characteristics of those mutations. A number of the genes associated with drug-resistance are naturally polymorphic, or their mutations 

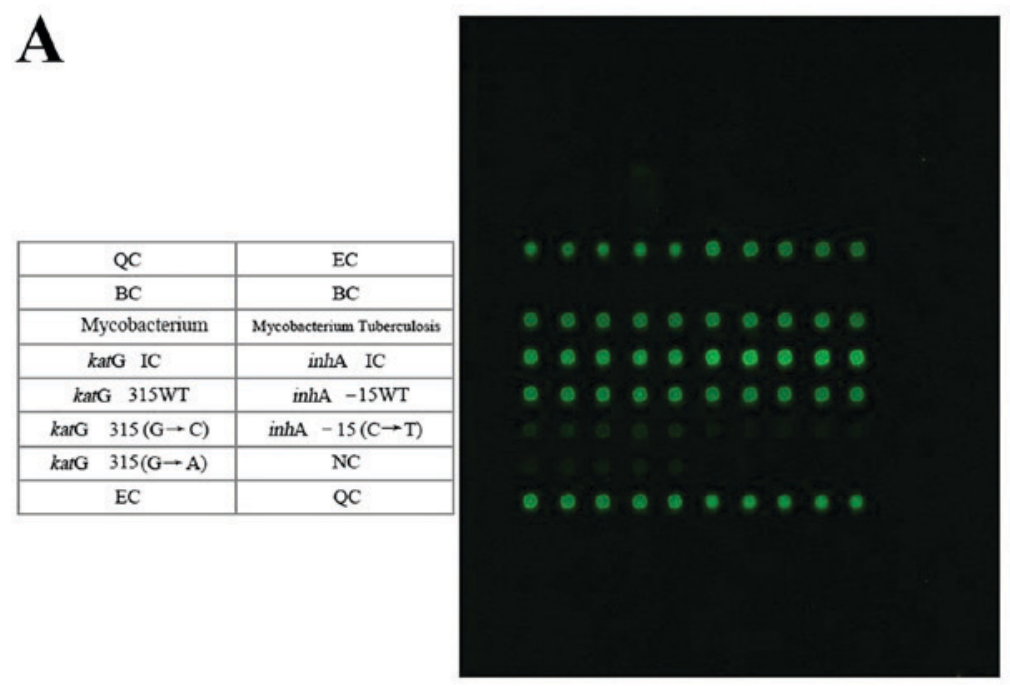

B

\begin{tabular}{|c|c|}
\hline QC & EC \\
\hline BC & BC \\
\hline Mycobacterium & Mycobacterium Tuberculosis \\
\hline karG IC & inhA IC \\
\hline katG 315WT & inhA -15 WT \\
\hline karG 315 $(\mathrm{G} \rightarrow \mathrm{C})$ & inhA $-15(\mathrm{C} \rightarrow \mathrm{T})$ \\
\hline karG 315 $(\mathrm{G} \rightarrow \mathrm{A})$ & NC \\
\hline EC & QC \\
\hline
\end{tabular}

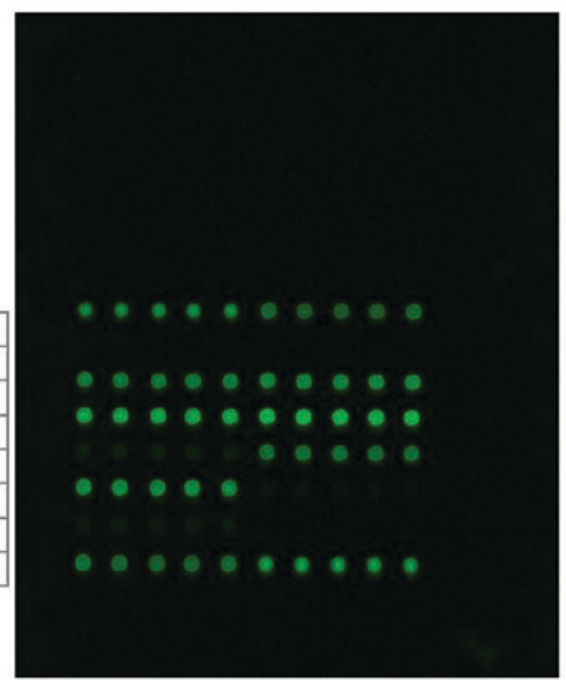

C

\begin{tabular}{|c|c|}
\hline QC & EC \\
\hline BC & BC \\
\hline Mycobacterium & Mycobacterium Tuberculosis \\
\hline karG IC & inhA IC \\
\hline karG 315WT & inhA -15 WT \\
\hline$k a r G 315(\mathrm{G} \rightarrow \mathrm{C})$ & inhA $-15(\mathrm{C} \rightarrow \mathrm{T})$ \\
\hline$k a r G \quad 315(\mathrm{G} \rightarrow \mathrm{A})$ & NC \\
\hline EC & QC \\
\hline
\end{tabular}

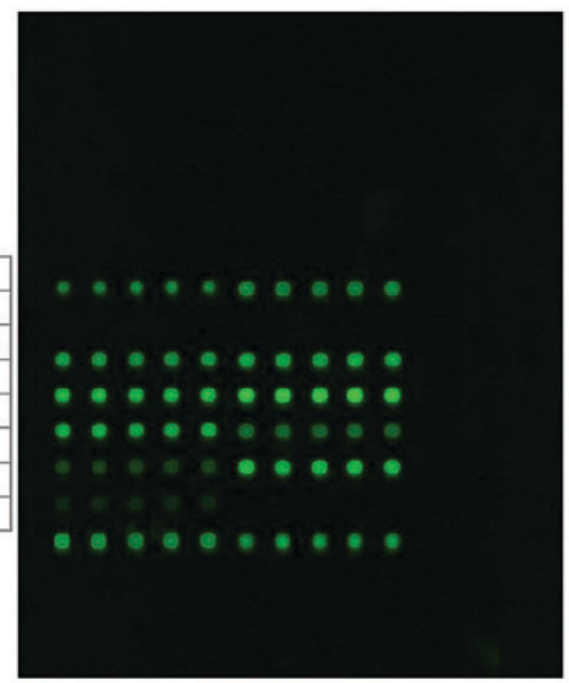

Figure 2. Microarray chip detection spectrums of the MTB katG315 and inhA-15 mutation points. The microarray chip detection spectrums are for samples with mutation(s) at: (A) WT MTB katG315 and inhA-15, (B) katG315 (AGC-ACC) and (C) inhA-15 (C-T). The contents of the table on the left side correspond to the microarray hybridization dot matrix on the right side in each figure. Every five repeated hybrid grid points correspond to one cell of specific content. MTB, Mycobacterium tuberculosis; WT, wild type; QC, chip preparation quality control; EC, chip hybridization quality control; BC, blank comparison quality control.

are not always associated with drug resistance; therefore, this may result in false positives using PCR-SSCP and other similar techniques (21).
DNA microarray chips comprise a molecular biological technique that has been developed since the 1990's. The technique has been used widely for multiple applications due to its 
rapidness, accuracy, high efficiency and easy operation (20). For different mutations, the corresponding oligonucleotide probes are designed and immobilized on a solid support. The gene fragments that contain the mutations are amplified by PCR and then hybridized with the gene microarray chips. As a large number of probes may be located on the solid support at the same time, numerous sample sequences may be detected and analyzed simultaneously. This technique addresses the shortcomings of traditional nucleic acid blotting techniques, a low degree of automation, small number of operating sequences and low detection efficiency. Along with the subsequent identification of genes associated with MTB drug-resistance and their relevant mutation sites, a number of previous studies have considered the application of DNA microarray chips for the detection of MTB drug-resistance. A total of 12 genes associated with drug-resistance for 5 first-line and second-line anti-TB drugs, including fluoroquinolones, have been detected and analyzed. Based on the molecular mechanisms of MTB drug-resistance associated with the gene mutations, gene chips are designed to detect drug-resistance-related genes and MTB drug-resistance may be judged by the detected mutations $(22,23)$.

RFP and INH are bactericidal drugs and comprise a drug combination that has long been effective. Numerous RFP resistant strains of MTB that result from $r p o B$ gene mutations are also resistant to INH (24). $>95 \%$ of RFP resistance related gene mutations were identified in the $r p o B$ gene-RRDR and $\sim 85 \%$ of the strains resistant to drugs had mutations on the 531 Ser, 526 His and 516 Asp codons in the RRDR. Based on this, the GeeDom Mycobacterium tuberculosis drug detection kits were used to analyze the mutations and relevant drug-resistance of the $r p o B$ gene RRDR 511, 513, 516, 526, 531 and 533 mutation sites, in the samples from patients in Soochow City, China. The results were compared with those derived using the absolute concentration method. The susceptibility and specificity of the DNA microarray chip to RFP sensitivity was 92.3 and $93.8 \%$, respectively.

INH is a first-line anti-TB drug that is used together with RFP. A study previously demonstrated that multidrug-resistance resulting from double-drug resistance to INH and RFP was the primary reason for refractory TB (25). Based on the prevalence of katG315 and inhA-15 mutations in the strains resistant to the drugs and their relevance to INH resistance, in addition to previous results (26), the primary mutation mechanism of INH-resistance in the MTB katGgene investigated was $315 \mathrm{AGC} \rightarrow \mathrm{ACC}, \mathrm{Ser} \rightarrow \mathrm{Thr}(\mathrm{S} 315 \mathrm{~T})$. GeeDom Mycobacterium tuberculosis drug detection kits were used to detect the INH resistance of the MTB clinical strains, and the results were compared with those derived using the absolute concentration method. The susceptibility and specificity of the DNA microarray chip to INH sensitivity was 66.7 and $81 \%$, respectively. The susceptibility of the DNA microarray chip to INH sensitivity was relatively low, which may be due to the INH resistance mechanisms being associated with multi-gene mutations.

The results of a few of the drug sensitivity tests were not consistent. This may be because the samples had primary (natural) drug resistance, rather than drug resistance caused by gene mutations. Natural drug resistance occurs due to the barrier mechanism, consisting of an extracellular multilayer coating and an active multidrug efflux ion pump, disturbing drug transportation by the MTB $(27,28)$. Alternatively, the inconsistency may have arisen because gene mutations occurred outside the detection range, resulting in RFP and INH resistance. For example, a few mutations have previously been identified in the $\mathrm{C}$ II and C III regions at N-terminal end of the rрoB gene, outside the RRDR $(12,29)$, resulting in RFP resistance. In addition, gene mutations other than kat $G$ and inhA-15 (like KasA, $n d h$ and $a h p C$ ) may result in INH resistance (and these were not tested for in the present study). Mutations may have also happened within detection range (RRDR-511, 513, 516, 526, 531 and 533), but may not have consisted of the detected mutation forms. For example, the detection for the 526-codon mutation point only included four forms, which were CAC $\rightarrow$ TAC, GAC, CTC and CGC4; however, there are other known possible mutations of this point, including $\mathrm{CAC} \rightarrow \mathrm{AAC}$.

In addition, the mutation rate that occurred during the detection of the strains sensitive to INH and RFP may have been caused by a difference in the drug concentration. That is, the drug concentrations in the absolute concentration method were high. Strains that were detected as drug sensitive through the absolute concentration method may have been drug resistant under lower drug concentrations. It is possible that the mutation of drug-resistant strains only happened at low drug concentrations. If this were the case, the detection of RFP and INH resistance by the GeeDom Mycobacterium tuberculosis drug detection kits may not achieve $100 \%$ accuracy, compared with the absolute concentration method.

Ultimately, the susceptibility and specificity of the DNA microarray chip to RFP resistance was 92.3 and $93.8 \%$, respectively, which is high and has great significance for the rapid detection of resistance in clinical applications. In conclusion, a DNA microarray chip may be developed as an effective method for the rapid screening of MTB resistance to RFP and INH, specifically for RFP resistance. This was effective in Soochow City, and has great significance for the clinical rapid diagnosis of MTB and subsequently treating TB patients with effective drugs against MTB as early as possible.

\section{Acknowledgements}

The present study was supported by grants from the Year 2014 Suzhou City Key Clinical Disease Diagnosis and Treatment Technology Special Project (grant no. LCZX201314), Year 2014 Jiangsu Province Association of Preventive Medicine Scientific Research Project (grant no. Y2013023), Year 2015 Suzhou City Key Clinical Disease Diagnosis and Treatment Technology Special Project (grant no. LCZX201414) and Suzhou Municipal Health Bureau Hygiene Project through Science and Education (grant no. KJXW2013033).

\section{References}

1. Maimaiti R, Zhang Y, Pan K, Mijiti P, Wubili M, Musa M and Andersson R: High prevalence and low cure rate of tuberculosis among patients with HIV in Xinjiang, China. BMC Infect Dis 17: $15,2017$.

2. Timmins GS and Deretic V: Mechanisms of action of isoniazid. Mol Microbiol 62: 1220-1227, 2006. 
3. Ranguelova K, Suarez J, Magliozzo RS and Mason RP: Spin trapping investigation of peroxide-and isoniazid-induced radicals in Mycobacterium tuberculosis catalase-peroxidase. Biochemistry 47: 11377-11385, 2008.

4. World Health Organization (WHO): Anti-tuberculosis drug resistance in the world. Fourth global report. WHO, Geneva, 2008.

5. Yu X, Shen X, Tang P, et al: Analysis of multi-drug resistance of Mycobacterium tuberculosis derived from tuberculosis patients in Suzhou city. J Clin Pulmon Med 17: 269-270, 2012.

6. Li G: The study of drug sensitivity for mycobacteria, Modern phthisiology. Beijing, PLA Medical Publication, pp36-57, 2000.

7. Carbonnelle B and Carpentier E: Bacteriological diagnosis of tuberculosis: Current hieratic classification of methods. Rev Med Interne 16: 518-523, 1995 (In French).

8. Demers AM, Venter A, Friedrich SO, Rojas-Ponce G, Mapamba D, Jugheli L, Sasamalo M, Almeida D, Dorasamy A, Jentsch U, et al: Direct susceptibility testing of Mycobacterium tuberculosis for pyrazinamide by use of the bactec MGIT 960 system. J Clin Microbiol 54: 1276-1281, 2016.

9. Ramaswamy S and Musser JM: Molecular genetic basis of antimicrobial agent resistance in Mycobacterium tuberculosis: 1998 update. Tuber Lung Dis 79: 3-29, 1998.

10. Scarpellini P, Braglia S, Carrera P, Cedri M, Cichero P, Colombo A, Crucianelli R, Gori A, Ferrari M and Lazzarin A: Detection of rifampin resistance in Mycobacterium tuberculosis by double gradient-denaturing gradient gel electrophoresis. Antimicrob Agents Chemother 43: 2550-2254, 1999.

11. Herrera L, Jiménez S, Valverde A, García-Aranda MA and Sáez-Nieto JA: Molecular analysis of rifampicin-resistant Mycobacterium tuberculosis isolated in Spain (1996-2001). Description of new mutations in the rpoB gene and review of the literature. Int J Antimicrob Agents 21: 403-408, 2003.

12. Van Der Zanden AG, TeKoppele-Vije EM, Vijaya Bhanu N, Van Soolingen D and Schouls LM: Use of DNA extracts from Ziehl-Neelsen-stained slides for molecular detection of rifampin resistance and spoligotyping of Mycobacterium tuberculosis. J Clin Microbiol 41: 1101-1118, 2003.

13. Harding CV and Boom WH: Regulation of antigen presentation by Mycobacterium tuberculosis: A role for Toll-like receptors. Nat Rev Microbiol 8: 296-307, 2010.

14. Kleinnijenhuis J, Oosting M, Joosten LA, Netea MG and Van Crevel R: Innate immune recognition of Mycobacterium tuberculosis. Clin Dev Immunol 21: 405310, 2011.

15. Bostanabad SZ, Nojoumi SA, Jabbarzadeh E, Shekarabei M, Hoseinaei H, Rahimi MK, Ghalami M, Pourazar Dizji S, Sagalchyk ER and Titov LP: High level isoniazid resistance correlates with multiple mutation in the katG encoding catalase proxidase of pulmonary tuberculosis strains from the frontier localities of Iran. Tuberk Toraks 59: 27-35, 2011.

16. Cade CE, Dlouhy AC, Medzihradszky KF, Salas-Castillo SP and Ghiladi RA: Isoniazid-resistanee conferring mutations in Mvcobacterium tuberculosis katG: Catalase, peroxidase, and INH-NADH adduct formaion activities. Protein Sci 19: 458-474, 2010.
17. Seifert M, Catanzaro D, Catanzaro A and Rodwell TC: Genetic mutations associated with isoniazid resistance in Mycobacterium tuberculosis: A systematic review. PLoS One 10: e0119628, 2015.

18. Khosravi AD, Goodarzi H and Alavi SM: Detection of genomic mutations in katG, inh A and rpoB genes of Mycobacterium tuberculosis isolates using polymerase chain reaction and multiplex allele-specific polymerase chain reaction. Braz J Infect Dis 16 : 57-62, 2012.

19. Lin SY, Hwang SC, Yang YC, Wang CF, Chen YH, Chen TC and Lu PL: Early detection of Mycobacterium tuberculosis complex in BACTEC MGIT cultures using nucleic acid amplification. Eur J Clin Microbiol Infect Dis 35: 977-984, 2016.

20. Al-Rubaye DS, Henihan G, Al-Abasly AK, Seagar AL, Al-Attraqchi AA, Schulze H, Hashim DS, Kamil JK, Laurenson IF and Bachmann TT: Genotypic assessment of drug-resistant tuberculosis in Baghdad and other Iraqi provinces using low-cost and low-density DNA microarrays. J Med Microbiol 65: 114-122, 2016.

21. Ali IF, Babak F, Fazlollah MS and Nematollah JJ: Rapid detection of MDR-Mycobacterium tuberculosis using modified PCR-SSCP from clinical Specimens. Asian Pac J Trop Biomed 4 (Suppl 1): S165-S170, 2014.

22. Linger Y, Kukhtin A, Golova J, Perov A, Lambarqui A, Bryant L, Rudy GB, Dionne K, Fisher SL, Parrish N and Chandler DP: Simplified microarray system for simultaneously detecting rifampin, isoniazid, ethambutol, and streptomycin resistance markers in Mycobacterium tuberculosis. J Clin Microbiol 52: 2100-2107, 2014

23. Shi XC, Liu XQ, Xie XL, Xu YC and Zhao ZX: Gene chip array for differentiation of mycobacterial species and detection of drug resistance. Chin Med J (Engl) 125: 3292-3297, 2012.

24. Ohno H, Koga $\mathrm{H}$ and Kohno S: Multidrug-resistant tuberculosis. 2. Mechanisms of drug-resistance in Mycobacterium tuberculosis-genetic mechanisms of drug-resistance. Kekkaku 73 657-663, 1998 (In Japanese).

25. Wang SF, Zhao B, Song YY, Zhou Y, Ou XC, Li Q, Xia H, Pang Y, Duanmu HJ, Fu Y and Zhao YL: Risk factors for drug-resistant tuberculosis in China: analysis of the results of the national drug resistant tuberculosisbaselinesurvey in 2007. Chin J Antituber 35: 221-226, 2013.

26. Van Rie A, Warren R, Mshanga I, Jordaan AM, van der Spuy GD, Richardson M, Simpson J, Gie RP, Enarson DA, Beyers N, et al: Analysis for a limited number of gene codons can predict drug resistance of Mycobacterium tuberculosis in a high-incidence community. J Clin Microbiol 39: 636-641, 2001.

27. De Rossi E, Aínsa JA and Riccardi G: Role of mycobacterial efflux transporters in drug resistance: An unresolved question. FEMS Microbiol Rev 30: 36-52, 2006.

28. Danilchanka O, Mailaender C and Niederweis M: Identification of a novel multidrug efflux pump of Mycobacterium tuberculosis. Antimicrob Agents Chemother 52: 2503-2511, 2008.

29. Heep M, Brandstätter B, Rieger U, Lehn N, Richter E, Rüsch-Gerdes S and Niemann S: Frequency of rpoB mutations inside and outside the cluster I region in rifampin-resistant clinical Mycobacterium tuberculosis strains. J Clin Microbiol 39: 107-110, 2001. 